\title{
Research and Exploration of Network Distance Teaching of Colleges and Universities Under the Novel Coronavirus Pneumonia Epidemic
}

\author{
$\mathrm{Li} \mathrm{Li}^{1, *}$ Musong $\mathrm{Gu}^{1}$ Xiujun Zhang ${ }^{1}$
}

\author{
${ }^{1}$ School of Computer Science, Chengdu University, Chengdu, Sichuan, China \\ *Corresponding author. Email: 527325276@qq.com
}

\begin{abstract}
The novel coronavirus pneumonia epidemic has pushed the model of distance teaching under the Internet + environment to the forefront of teaching. Therefore, it is necessary to re-understand distance teaching. In the process of this, it is necessary to grasp the key points such as the feasibility of operation, the convenience of practical highlighting, the real-time interaction and the pertinence of feedback. This paper takes the Chaoxing Learning Pass as an example, mainly introduces its application in distance teaching during the epidemic period, with good effect, and analyzes the advantages and disadvantages of the Chaoxing Learning Pass. It aims to provide reference materials for distance teaching researchers. It is believed that in the near future, online course teaching and offline classroom teaching will be integrated into one, further enriching and improving the teaching means and mode, to achieve peopleoriented intelligent teaching, in order to promote the rapid development of teaching.
\end{abstract}

Keywords: distance learning, Chaoxing Learning Pass, network teaching

\section{INTRODUCTION}

Distance teaching refers to a kind of teaching activity that teachers and students carry out with the help of multimedia technology under the condition of non-face-to-face teaching. It is different from the traditional on-campus learning in colleges and universities. Students can learn by correspondence, special counseling line, TV broadcast, Internet and other different channels, breaking through the boundary between traditional teaching and time and space. At the beginning of 2020, after the rapid spread of the novel coronavirus pneumonia across the country, local communities were under closed management. In such a tight community management environment, students could only choose to study at home. The Ministry of Education also made a decision to delay the start of the school year, and explicitly required universities to transfer the offline courses to the online ones, so as to "delay the start of the school year and not stop teaching". At present, China's Internet technology is highly developed, the network distance teaching has been very popular, in the normalized before teaching, online courses only can be used as a form of traditional teaching, but in today's epidemic state, was forced to stop all daily teaching, the network distance teaching has gradually become the main teaching of universities. Many colleges and universities are using the Internet remote live or online teaching methods to ensure that the original teaching progress, although this is very good effective in relieving the tensions of the time, but still obviously there are a lot of disadvantages, such as the live webcast due to network latency when serious, the phenomenon of delayed frames in often appear images, students and the instructor interactivity is not strong and so on. For the teaching teachers, without strict training, they may directly become network anchors in a short period of time, which may lead to various situations and problems on the Internet. For college students, they may be very curious about the feeling of live teaching at the beginning, and gradually they will feel bored. Based on the above reasons, our school adopts the distance teaching mode combining the Chaoxing Fanya Teaching Platform and Chaoxing Learning Pass APP, which has achieved good teaching effect.

\section{INTRODUCTION OF CHAOXING FANYA Teaching Platform}

Chaoxing Fanya Teaching Platform was developed by our country independent an integration of online teaching curriculum management platform and the wisdom of the integration of interactive teaching and teaching platform, the teacher can upload teaching learning materials, assignments or generating test paper, in the group chat or discussion and interaction with the exchange of students, to see the students' learning activities of data statistics, management and guiding students' learning behavior, etc. All teaching activities 
of teachers and students will be carried out and recorded in detail on this platform, so as to facilitate students' self-study and teachers' supervision and supervision.

Chaoxing Learning Pass is an APP for smart phones, tablets and other mobile terminals. User after installation can be done on the Chaoxing Learning Pass through self-help Chaoxing digital library, the library borrowing information query, electronic resources, library database search and download information browsing, learning the lessons of the school, group discussion, to see the school directory, at the same time it also has a huge number of electronic books, newspaper, journal articles as well as the domestic and foreign relevant academic literature metadata, and students to provide convenient and quick for users of mobile learning services. The most significant advantage of Chaoxing Learning Pass is that it can help every zero-basis teacher quickly build a course of his/her own, with abundant available resources, convenient interaction with students, and timely data analysis and statistics.

\section{A. Application of Chaoxing Learning Pass in distance teaching}

During the emergency period, the school term is delayed, and teachers should complete the teaching tasks on time. Each teacher needs to formulate the network distance teaching plan to realize the network teaching quickly. Chaoxing Learning Pass easy "five steps" to help teachers complete the recording of "online lesson", management of online lesson, teaching, homework test learning effect, etc.

The first step is to sign in. In the mobile application market, you can search the system keyword " Chaoxing Learning Pass ", and download and install directly according to the system prompts. After the installation process is opened, the system administrator will register and $\log$ in according to the prompts, and enter the correct personal mobile phone number and verification code to indicate the completion of the registration and installation

The second step is to build classes. Open the " + " in the upper right corner of Chaoxing Learning Pass Guide, click "New Course ", just input the corresponding course name and QR code directly, click" Finish ", and the basic teaching framework of a course has been completed. In an unusual period, teachers have a tight time and heavy task to build lessons. Therefore, it is still possible to build lessons quickly by creating demonstration teaching packages. Demonstration teaching package is a unit of course, that is, a course for a teaching class demonstration teaching package. The purpose and purpose of this demonstration teaching package is to meet the various resource needs of teachers in teaching and guiding students in the process of autonomous learning, and to reduce the teaching pressure and workload of teachers before, during and after class. To provide students with interesting, multimedia classroom learning environment and materials. At the same time, teachers can also select classes to build lessons and carry out online teaching, which greatly reduces the workload of teachers. After the course construction is completed, the teacher also needs to set up several classes according to their own classes to conduct online teaching management. At this time, we only need to directly find the class in the teaching management page of building a course, and then we can add several teaching classes at the same time and conduct online teaching and editing for them. At this time the teacher just need to give students the class or QR code send invitation code, students only need to input class invited yards or scan QR code already can directly join my class, the teacher in the course of sending any notice or any organization activities, students can receive timely and view.

Third, add data. To find materials on the frame page of the course, you can add PPT, Word and video through various channels. The corresponding content can be set as task points, and the video can be anti-drag, anti-window switch and in-situ playback. At this point, students in the class can view the added information. Teachers can also share with a single click to a specified class or add to a chapter with a single click. Students can use the fragmented time to learn these materials anytime and anywhere. Learning is not limited to 45 minutes in class, so that students feel learning is a habit rather than a task. After a long time, they can experience the joy of learning knowledge, and the learning in class will become relatively easy and easy.

Step 4: Classroom interaction. Before the formal class, each student can be informed of the preview content and the specific time and process of the formal class. Because distance teaching cannot grasp the knowledge and attendance of each student in real time, it is necessary for the teacher to let each student sign in before the formal class, such as QR code sign in, gesture QR code sign in, location sign in and so on. Teachers can be set automatically sign in the time and place of specific knowledge and video viewing for each student in real time, watch video against drag, can automatically set the window switch, must achieve remote video to watch for more than $90 \%$ to the qualified teachers can also to master each of the students in remote real-time background knowledge and watch the video. Remote viewing video is finished, the teacher in class with each student to the problem are discussed, the corresponding knowledge point set students grouped tasks, vies to answer first, and the candidates, let each student profound experience and classroom in the classroom of offline, the teacher is in the side, but also can attract the attention of each 
student and attention, have increased interest in classroom teaching, cultivate the students' ability of logical thinking. For the key points and difficult points in class, the teacher can automatically use the function of whiteboard in class, which is as clear and intuitive as the students' writing on the classroom blackboard. After learning a unit or a chapter, teachers can take a test, questionnaire or vote. Teachers can answer questions or explain the key and difficult points according to the test situation. At the end of the course, the teacher can issue assignments that can be completed by the students at a specified time. The objective question system automatically corrects and gives corresponding scores, so that students can see where they are wrong and have a good idea. The subjective questions should be read by teachers or read by students from each other, and corresponding scores should be given. This greatly lightens the workload of teachers in correcting homework. Teachers can also record and evaluate their classroom performance and classroom exercises, so as to form an open, pluralistic and democratic learning atmosphere, which will enable teachers to better discover the needs of students and thus encourage them to make continuous progress. Through smart phones, classroom teachers and students are closely linked together, making the interaction and communication between teachers and students more convenient, more efficient, more fully reflect the "student-centered" classroom teaching philosophy. After class, teachers and students who have any questions can ask and consult teachers through mobile phone group chat or private chat, which reduces the relationship and distance between teachers and students in class and enhances the understanding and affection between teachers and students.

Step 5, teaching achievement statistics. At the end of each course, by clicking on the "Statistics" interface, teachers can timely get relevant statistical information about students' class discussions, classroom activities, chapter audio visits, video visits, homework and other achievements, and accurately grasp the classroom learning situation and dynamics of each teacher and student. For excellent students with low classroom participation rate, teachers can remind them in class, supervise and guide them to learn, and give appropriate praise to excellent students who perform well in class, which is also a good incentive for other students. By automatically setting the scores and weights of each achievement statistic, the system automatically obtains a score that forms an objective and fair "achievement statistic". Such statistical activities can fully stimulate students' enthusiasm and interest in classroom learning, enhance students' active initiative in classroom learning, and effectively greatly improve the efficiency of learning.

\section{B. Advantages and disadvantages of Chaoxing Learning Pass through distance class}

Mobile terminal mobile learning pass is more popular among college students. Although many teachers have built many online learning resource sharing platforms for teaching, our survey found that most of them were used to participate in teaching competitions or cope with teaching inspection, but few of them were actually used. One of the biggest drawbacks is that online and offline cannot be combined effectively, and mobile terminal Chaoxing Learning Pass just effectively solves this problem. At the same time, students can also study by browsing the web pages of computers or using mobile phones. The survey found that $98 \%$ of students prefer to study with smart phones. Although mobile phones have always been regarded as a stumbling block to students' learning, the rapid advancement and development of informatization has always made everyone inseparable from smart phones. We used the learning tool APP that college students are very interested in to directly turn this stumbling block into a learning tool. College students have a strong ability to accept new things. A new learning tool APP is very familiar to them in a short while. They can directly use the fragmented time to learn, which increases the learning time of students in a disguised way. As students are supported to use smart phones, students' learning activity enthusiasm, learning progress and learning efficiency are also greatly improved. Of course, this also puts forward higher requirements for teachers, who need to prepare more abundant course resources so that students can fully carry out diversified online learning. The emergence of mobile intelligent terminal Chaoxing Learning Pass Link facilitates the information exchange between teachers, students and students in schools, and changes the way teachers teach and students learn. However, the negative factors it brings should not be underestimated. Many college students have poor selfcontrol and poor independent learning ability. For the reason of studying, watching TV dramas or playing games on their mobile phones every day will do no good to their physical study. In the online class, teachers should also have a good time to use the Learnto-learn APP to prevent students from fishing in troubled waters.

\section{Problems in distance eduCation UNDER THE NOVEL CORONAVIRUS PNEUMONIA EPIDEMIC}

\section{A. The change of teaching environment makes both teachers and students in a bad state}

During the outbreak across the country, teachers and students taught online in their own homes. The change of teaching place has great influence on teachers' teaching and students' learning status. First of all, 
teachers have independent families. They are not only responsible for teaching, but also for daily family work. Network teaching at home, the external environment has a great impact on its teaching, so that teachers can not focus on teaching. In addition, in home isolation, living schedule will indirectly affect the teaching status of teachers. Students who study at home and attend distance classes are also unable to concentrate on the learning of textbooks due to the differences between the classroom environment at home and at school. At the same time, students are used to carrying out entertainment and leisure activities through the Internet, and they cannot achieve good memory and understanding effect for a long time of online teaching. Such differences in environmental cognition exist widely in the student group, and educators should take this into full consideration when conducting online teaching.

\section{B. Distance teaching cannot make teachers and students interact well}

In Internet distance teaching, teachers teach online through the Internet or video. Teachers cannot have direct interaction with other students as we traditionally do in class. Therefore, the traditional network distance teaching in class cannot help students to ask questions and test in class easily. In addition, teachers taught in the traditional class at will and emotion and activity, and the classroom environment and atmosphere is there much of a close relationship, in the traditional classroom teaching activities, teachers will and high emotion expressed by the content and effect, and has a strong visual appeal for students, students in the classroom can also deeply felt the teacher this emotion infection, energy absorbed into classroom learning. In the network distance education, it is difficult to achieve this effect. Teachers and students use video call, there is a strong sense of distance between them.

\section{The limitations of equipment and technology affect the effect of network teaching}

Network teaching technology completely relies on intelligent equipment and network. At present, China's network technology has been quite mature, but there are still some areas of network coverage degree is not good, because of the network base station coverage force is insufficient and other reasons, the remote mountainous area and the city network coverage state is far from. In network teaching, network delay and lag caused by technical reasons will bring great trouble to teachers' teaching. In addition to the network, the computer hardware equipment is also very important. In the network distance teaching, teachers and students must have video and audio equipment, teachers and students can receive each other's video and audio information. Teachers leading online teaching activities must ensure the output effect of audio. If necessary, teachers need to install professional audio equipment to effectively express the teaching content. Not receiving video and audio in time due to network technology and equipment will cause the quality of the class to decline, and even cause problems in communication.

\section{Teaching effect is the lack of feedback and management}

The network distance teaching, teachers' online teaching lacks effective feedback. When teachers teach online, they cannot communicate with students in a timely manner, and they cannot understand students' reactions in class. It is also unable to carry out some regular classroom interactions and tests in classroom teaching effectively, such as random questions asked by teachers in class, assignments and explanations in class. In addition, it is difficult to supervise and manage students' homework after class, and students can only rely on their own initiative to complete it. It is also difficult for students to consult and communicate with teachers in time about the difficulties and problems they may encounter in reading exercises after class. The sense of distance generated by online distance courses makes teachers lack effective supervision and management of students' learning state, and makes students have subtle changes in psychology, which leads to the loss of constraints and learning initiative, and reduces students' learning enthusiasm and efficiency.

\section{COUNTERMEASURES TO SOLVE THE PROBLEM OF DISTANCE LEARNING DURING THE EPIDEMIC}

\section{A. Setting regular teaching and learning times}

In the network teaching during the home isolation period of the epidemic outbreak, in order to improve the working and learning status of teachers and students to the greatest extent, regular work and rest time should be established during the home. The content of the regulation is made by the teaching department and implemented by teachers and students consciously. The arrangement of work and rest time should be as scientific and reasonable as possible, which should not only coincide with the normal teaching time, but also take into account the particularity of the epidemic period. For example, in order to focus students' attention and take into account the visual health of students and other problems, the time of each class should be limited to about 30 to 40 minutes, and the break time should be 10 to 15 minutes. It is suggested that students do some simple exercises in the room to relieve eye and limb fatigue. Reasonable arrangement of their own work and rest time, can effectively improve the efficiency of teachers and students study, 
so that teachers and students in the isolation of learning at home to maintain a good physical and mental state.

\section{B. Expanding classroom teaching methods and skills}

During the epidemic period, the form of online distance education was relatively simple, and it was difficult for teachers and students to communicate online through computer screens, so it was difficult to achieve the audio-visual effect in traditional classes. Because some students are not used to this kind of learning form, they have some problems such as lack of attention and difficulty in thinking. Teachers should rely on the form of online teaching, as far as possible to expand a variety of teaching methods and skills, to increase the interest and enjoyment of teaching. For example, with the support of video technology, teachers and students can interact with some bullet screen or animated expressions to effectively highlight the learning atmosphere of the whole class.

\section{Strengthening hardware and technical support}

In network teaching, hardware equipment and network technology are the basic requirements of network teaching. In the network teaching, to ensure the efficient operation of teaching equipment. In the context of the outbreak of epidemic disease in China, the teaching management departments of colleges and universities require that every online teaching teacher must check the computer and network equipment of his or her own home in advance before arranging online teaching, so as not to affect the normal online teaching. Institutions of higher learning should establish sound organizations to deal with the epidemic, provide logistics support for online teaching, and solve the problems of network and equipment in online teaching. For example, on the premise of meeting the overall quarantine measures during the epidemic, colleges and universities can arrange technicians to inspect and install hardware equipment and network at teachers' homes. For teachers living in other cities, teachers are required to directly purchase relevant equipment locally and conduct installation and debugging under the remote guidance of technicians.

\section{Establishing a feedback mechanism in line with online teaching}

In the network teaching, we must strengthen the feedback of teaching effect by means of technology and management. First of all, it is necessary to establish a network teaching management mode that meets the requirements of network teaching through network monitoring technology. The teacher asks the students to give feedback on the teaching content on the Internet platform or other online forms. The daily attendance and sign-in procedures can be formulated, and students are required to investigate the corresponding knowledge points, and the background monitoring can be carried out through the online system. Teachers can also collect feedback information from students through online network platforms, or ask students to comment on the form of online teaching through questionnaires, put forward improvement methods for existing problems, pool wisdom, and constantly improve the model of online teaching.

\section{CONCLUSION}

During the epidemic period, although the normal teaching work of colleges and universities is interrupted the network distance teaching can become an important form to guarantee the normal teaching of colleges and universities. Educators should make good use of modern information technology to serve students. In order to cultivate and improve the students' classroom learning interest and efficiency, teachers should first guide the students to renew the concept of classroom teaching, learn advanced classroom information teaching technology and apply it to our classroom. Second lead teachers also need to fully prepare guidance of class activities, class lively and interesting, so as to draw attention to the teacher and the students interest and adequately, mobilize teachers to guide students to classroom learning interest and enthusiasm, take the student as the main body, to guide students from Internet addiction to use web platform to learn, enhance interest in learning, improve the learning efficiency; Colleges and universities should constantly improve the mechanism of coping with the outbreak of the epidemic, and constantly try and optimize the new form of network distance teaching in the daily teaching of colleges and universities, so that the network distance teaching becomes an important auxiliary teaching means for colleges and universities, and ensure the normal operation of network distance teaching in the teaching work of colleges and universities in the case of the outbreak of the epidemic

\section{Acknowledgment}

This paper is one of the phased achievements of the first batch of key projects on the collaborative development and education of higher education (Project No.: 201801200044, Project No.: 201801193140) of the Ministry of Education of the State Council in 2018.

This paper is a study project on collaborative innovation development and Talent Cultivation of the second batch of undergraduate education cooperation exchange, teaching and Research Cooperation characteristic education project of Ministry of Education, Tsinghua University, China in 2018 (Project No.: 201802092031; Project No: 201802271037).

This paper is one of the stage results of 2018-2020 Higher Education Talent Training Quality and Teaching Reform project of Education Department of Sichuan 
Province. Project Title: Research and Practice of indepth integration of Innovation and Entrepreneurship Competition and Entrepreneurship Theory Courses based on Block chain Technology - Take computer major as an example( project No: JG2018-786).

This paper is one of the stage results of Chengdu's education and Scientific Research plan in 2020 is entitled "Novel coronavirus pneumonia Epidemic and Chengdu's Education Response". The project name : Research on the Innovative Teaching Practice of Distance Education in Colleges and Universities under Novel coronavirus pneumonia epidemic.(Project No: YQZX074).

This paper is one of the phased achievements of the first batch of "curriculum ideological and Political" school-level demonstration course project of Chengdu University (Project No: KCSZ2019028) and the first batch of "double-leader" studio construction project of Chengdu University (studio name: Gu Musong Studio of computer Teachers' Party Branch, no project No.).

\section{References}

[1] Lingxia Chen Xifeng Liao, "Based on the study of online hybrid Teaching ," China journal of Quality Education in the West, Vol.17, pp.99-100, May 2019.

[2] YongXia Zhang, JuanJuan Li, "Based on the super star turn learning through the classroom in the application of remote Teaching " China journal of Horizon of Science and Technology, Vol.20, pp.12-13, May 2020.

[3] ChunHua Song, "During the outbreak of the network teaching problems and composition," China Journal of heilongjiang Science, Vol.13, pp.112-113, November 2020.

[4] LiYuan Zhou, "Embedded Subject Service Discovery Based on Mobile Terminal," China Journal of Private Science and Technology, Vol.11: pp.117-118, 2017.

[5] Zilin Yang, Using the network platform to realize the new exploration of "stopping classes without stopping" teaching [J]. China Education Informatization, Vol.386: pp.90-91, December 2016

[6] Xiaodan Fei,Flipped Classroom Research on Vocational Professional Courses supported by Fanya -- Taking Statistical Technology course as an example [J]. E-commerce, Vol.13, pp.76, pp.94, December ,2018. 